\title{
The Influence of Vacuum Level on the Friction Force Acting on the Pneumatic Cylinder Sealing Ring
}

\author{
Branko TADIC, Milutin ZIVKOVIC, Goran SIMUNOVIC, Vladimir KOCOVIC, Tomislav SARIC, Djordje VUKELIC
}

\begin{abstract}
Presented in this paper are the results of measurement of friction force acting on the pneumatic cylinder sealing rings under high vacuum atmosphere. The investigations were conducted at relatively low levels of sliding speed of the sealing ring. Special device was constructed and implemented to facilitate this experiment. The results indicate the importance of the vacuum level on the friction force magnitude. Higher vacuum levels influence significant increase of friction force. Special phenomenon is the decreasing of friction force at higher sliding speeds of the sealing ring along the cylinder, under the constant vacuum level. Therefore, detailed examination of this phenomenon in the domain of high sliding speeds could yield interesting results.
\end{abstract}

Keywords: cylinder; sealing ring; sliding friction; vacuum

\section{INTRODUCTION}

There are an ever growing number of devices which operate under high vacuum. The development of such systems goes hand in hand with space program development and numerous industries involved. It is therefore necessary to know tribological characteristics of materials which are used for manufacture of such systems. Another source of motivation for the investigation of tribological characteristics of materials in specific environments is the already present technological requirements, as well as the need to identify materials with optimal tribological characteristics. Development of materials is also associated with the investigation of operating conditions under which the contacts take place, hence a number of investigations focusing on the atmosphere composition [1-3], atmospheric pressure [4-6], and temperature $[7,8]$.

The influence of atmospheric gases on friction and wear of pure metals, e.g. iron, titanium, nickel and gold, under various levels of atmospheric pressure, was investigated by Mishina [9]. With the change of the atmospheric pressure, the degree of gas absorption also changes for various metals, influencing, in turn, the wear and friction coefficient, primarily as the result of change in the wear mechanism. The products of wear which are present in high vacuum are typical for pronounced wear conditions [10]. These wear products firmly stick to the metal surface layer over prolonged periods of time, and cannot be easily removed. For that reason, the wear is less intensive, while the wear products are large-size metal particles.

The emergence of oxide layers has a pronounced influence on the wear and friction at the surface layer interface [11-13], while under vacuum conditions; the emergence of the oxide layers is not possible. The formation of oxide layers on the contact interface results in the lower friction coefficients. However, friction can be accompanied by the destruction of these layers and the change in the microstructure of contact interface layers. Iwabuchi et al. [13] concluded that friction coefficient increases with the lowering of atmospheric pressure, where the critical atmospheric pressure in fretting is $10 \mathrm{~Pa}$, and below it the degree of oxidation remains independent of the atmospheric pressure. In addition, the friction coefficient drops with the increase of oxide layer thickness on the contact surface interface. The wear is also diminished when the atmospheric pressure drops below the critical value. The critical value of $10 \mathrm{~Pa}$ which characterizes the relationship between friction coefficient and the change in atmospheric pressure, was also confirmed by Chen [5].

On the nano-level, friction is largely influenced by air humidity [14-16] as well as the water absorbed by the contact interface surfaces due to capillary action [17]. LFM determination of the impact of humidity on the friction at the nano-level, under the atmospheric pressure and vacuum, was reported in Bistac et al. [18]. In this case, the friction in vacuum decreases with the increase of sliding speed, while, under normal pressure conditions, the friction ramps up with the sliding speed, due to absorbed water at the contact interface layer.

Similar phenomena have been reported for diamond. It is well known that diamond exhibits low sliding friction coefficients (between 0,05 and 0,15 ) in air and atmospheric pressure, while in vacuum that value increases to values between 0,5 and 1 [19]. The reason for such behaviour is the atomic bonds between diamond contact interface layers [11]. Friction coefficient is almost 10 times greater in vacuum compared to that under normal atmospheric pressure, in air [20]. At the atmospheric pressure, in air, water and nitrogen molecules adhere to contact interface surfaces, forming tribological layers which prevent the direct interfacing of contact elements [21,22]. Thus formed, this tribological layer is the main reason for the lower friction coefficient and diminished wear under normal ambient conditions. The said layers come into existence primarily in the presence of lower contact pressures, while their thickness is reduced by the increased contact pressure. In vacuum, two clean surfaces form direct contact, due to breaking and degradation of the tribological layer. Miyoshi [23] claims that, during contact in vacuum, the atomically clean surfaces exhibit strong attractive forces, which results in increased friction coefficients.

Bronze and brass are the alloys very often used for slide bearings, so it is very important to know their behaviour in vacuum [24, 25]. Friction coefficient is higher in vacuum, and increases with the increase of contact pressure. This is in direct opposition to its behaviour in 
normal atmospheric pressure [25], where the contact surfaces quickly receive a layer of contaminants and oxide.

Rubber materials are widely used in industry due to their good mechanical properties, corrosion resistance, wear resistance, etc. [26, 27]. The tribological behaviour of the rubber in contact with other materials has been investigated in the last few decades. Anyszka et al. [28, 29] examined tribological properties of rubber-based ceramizable composites against steel under various load. Performed investigation demonstrated that tribological characteristics depend significantly on the origin of material. Friction force was increasing with an increase of the load. Deladi et al. [30] developed a static friction model for contact between rough rubber and metal surfaces. A model was based on the contact of a viscoelastic-rigid asperity couple. The traction distributions, contact area, tangential and normal displacement of two contacting asperities were calculated. Bielsa et al. [31] presented a finite element based methodology for obtaining pressure dependent friction laws from experimental tribometer tests on rubber-metal contacts. Tribometer tests were simulated for analyzing the area of contact and obtaining an approximation to the contact pressure distribution. Ke et al. [32] studied the mechanical behaviours of the tubular rubber seal under the curved surface loading. The results indicate that the physical parameters based on the experiment and finite element method simulation of the tubular rubber seal under the plane loading can describe the mechanical behaviour under the curved surface loading. Zhang and Zhang [33] measured the friction coefficients between rubber sealing ring and steel part, under different lubrication conditions. The effects of pre-compression, pressure, friction coefficient, and rubber hardness on sealing performance were discussed.

Several experimental and mathematical methods have been proposed to investigate the friction characteristics in the sliding regime of pneumatic cylinders. Belforte et al. [34] described the design of a test rig for measuring the friction force in pneumatic components and seal. Friction force was increased along with velocity and chamber pressures. Mazza and Belforte [35] presented an analytical for assessing friction forces in reciprocating seals for single and double rod pneumatic cylinders. The contributions of individual piston and rod seals were analysed using a combination of analytical and experimental approaches. Tran and Yanada [36] investigated dynamic behaviours of friction in the sliding regime of pneumatic cylinders. They developed model at various conditions of velocity variation and pressures. The experimental results showed that a hysteretic behaviour can be obtained at low velocities in the dynamic friction force-velocity relation and the friction force varies nearly linearly with the velocity at high velocities. Tran et al. [37] proposed a mathematical model of friction by incorporating a hysteresis function into the LuGre model. An experimental setup was made to measure friction force-displacement characteristics in pre-sliding state under various conditions of applied force and pressures in the cylinder chambers. Belforte et al. [38] described an experimental apparatus to measure the friction force in pneumatic cylinders. The results showed that the friction force increases with velocity and increases with an increase in driving pressure. In the tests where resistance pressure was changed, the friction force decreased with an increase in resistance pressure in the range of small velocities, and increased with an increase in resistance pressure in the range of high velocities.

In contrast to previous investigations, the goal of this study is to examine the influence of vacuum level on the friction coefficient exhibited by piston sealing ring, at various sliding speeds.

\section{THEORETICAL ANALYSIS}

Let us consider the loads on a piston cylinder under the existing difference in pressures on the left and right sides of the piston. Shown in Figure 1 is a simplified schema of force/pressure distribution. If, from its starting position (maximum retraction), the piston under force $F_{u}$ begins to move in the direction of the force vector - given that there is no air movement in front of the piston head - there will be a subpressure in the chamber before the piston head. The magnitude of that subpressure will depend on the chamber volume, piston head surface area, and piston travel. The emerging forces are marked in Fig. 1. Equilibrium equation for the given system is the following:

$F_{u}=F_{p}+F_{\mu k}+F_{\mu c}$

where: $F_{u}$ is total force which acts upon the connecting rod, $F_{p}$ is the force which results from pressure difference, $F_{u k}$ is sliding friction force between the sealing ring and inner surface of cylinder, $F_{\mu c}$ is sliding friction force between sealing ring and connecting rod.

a)

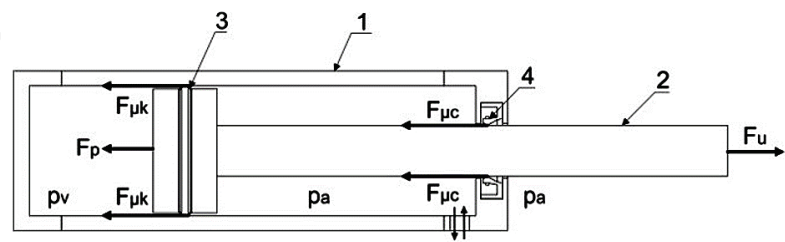

b)

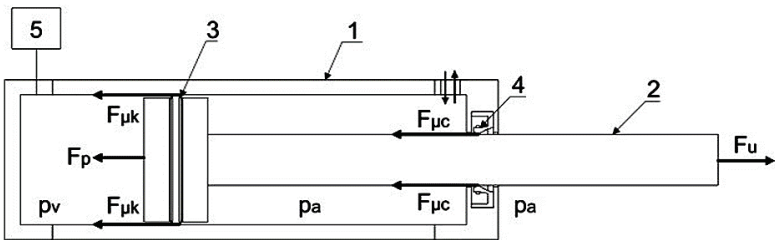

Figure 1 Forces and pressures distribution scheme - pneumatic cylinder a) with system for pressure regulation, b) without system for pressure regulation; 1 - cylinder, 2 - connecting rod, 3 - sealing ring between piston and cylinder, 4 sealing ring between connecting rod and cylinder, 5 - system for pressure regulation (system for subpressurization)

Considering that the piston surface is constant, $A=$ const., the magnitude of force $F_{p}$ is influenced only by the actual vacuum level, i.e., the difference in pressures $\Delta p$.

$F_{p}=A \cdot \Delta p$

Pressure difference $\Delta p$ equals:

$\Delta p=p_{a}-p_{v}$,

Since the piston features circular cross-section, there holds: 


$$
F_{p}=r^{2} \cdot \pi \cdot \Delta p
$$

where $r$ is the radius of piston head.

Knowing that the force resulting from pressure difference $\left(F_{p}\right)$ is calculated according to Eq. (4), while the total force magnitude is measured by a dynamometer, the only remaining unknown is the total friction force $\left(F_{\mu}\right)$ which consists of two components, $F_{\mu k}$ and $F_{\mu c}$. Where:

$$
F_{\mu}=F_{\mu k}+F_{\mu c}
$$

Given that the force between the sealing ring and connecting rod $\left(F_{\mu c}\right)$ is constant along the circumference due to equal pressures on both sides of the ring $\left(p_{a}\right)$, while the connecting rod's surface roughness has low variance in longitudinal direction, it is logical to assume that the friction force between the sealing ring and connecting rod $\left(F_{\mu c}\right)$ shall be approximately constant. From this follows that the total friction force $\left(F_{\mu}\right)$ varies exclusively due to changes in the sliding friction force between the piston sealing ring and cylinder $\left(F_{\mu k}\right)$, under the influence of subpressure.

Magnitudes of sliding friction force between the connecting rod and sealing ring $\left(F_{\mu c}\right)$, at various retraction speeds, can be experimentally established according to scheme in Fig. 2.
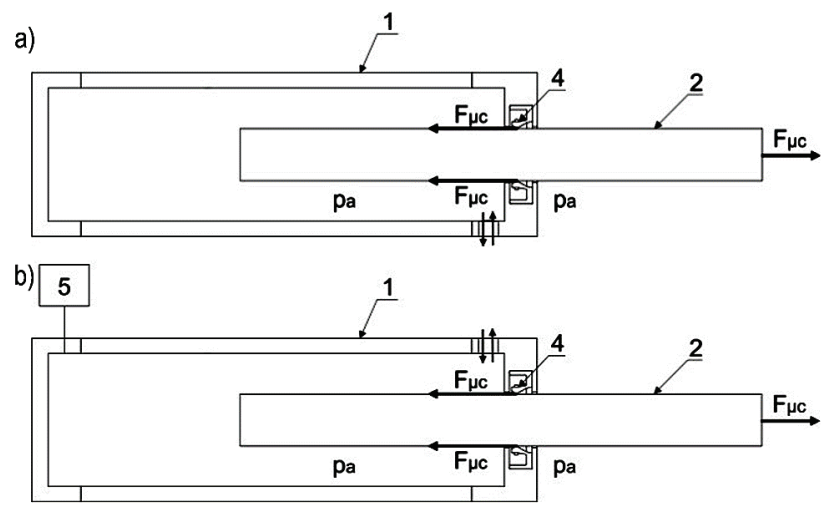

Figure 2 Forces and pressures distribution scheme - pneumatic cylinder without piston: a) with system for pressure regulation, b) without system for pressure regulation; 1 - cylinder, 2 - connecting rod, 4 - sealing ring between connecting rod and cylinder, 5 - system for pressure regulation (system for subpressurization)

Determination of sliding friction coefficient can be performed using identical measuring equipment, where the piston is disconnected from the connecting $\operatorname{rod}\left(F_{\mu k}=0\right)$, while the total force measured when the piston is open, represents the friction force between the connecting rod and sealing ring $F_{\mu}=F_{\mu c}$, given that $F_{\mu k}=0\left(p_{a}=p_{v}\right.$, i.e., $\Delta p=0)$. For the measured friction forces $F_{\mu}$ and $F_{\mu c}$, according to (5), one can calculate friction force, $F_{\mu k}$, based on the following equation:

$$
F_{\mu k}=F_{\mu}-F_{\mu c}
$$

\section{MEASURING INSTRUMENTATION}

A detailed scheme of experimental system's pneumatic circuit is given in Fig. 3. In order to experimentally measure the friction force in the reduced pressure atmosphere, a device was designed and constructed. This experimental system consists of two basic, separable systems - the measuring system, and the system for subpressurization.

Attached and fastened to the carrying framework of the measuring system is a pneumatic cylinder (9) with $40 \mathrm{~mm}$ inner diameter, and piston travel of $125 \mathrm{~mm}$. Piston is retracted by a stepper motor (17), via nuts (15) and belt (16), which is driving the threaded spindle (14) into one or the other side, depending on the direction of motor rotation (17). The link between the threaded spindle and connecting rod is established through dynamometer (12) which measures the retraction force of the connecting rod. The link between the threaded spindle and dynamometer is stiff, while the link between the dynamometer and connecting rod is flexible. This flexible link prevents measuring error due to possible prestressing of the dynamometer, i.e., it guarantees good repeatability of results. Dynamometer accuracy is $0.1 \%$ of full scale capacity, i.e $0,01 \mathrm{dN}$. Stepper motor operation is run by the control unit (18) which controls connecting rod's retraction and displays it on screen. Connected to the lower end of the pneumatic cylinder - through a coupling, reducer, hose and sealing rings - is the vacuum meter (10) which indicates the subpressure within the measuring system. By means of couplings, hose, and valve, another connecting branch maintains the link between this measuring system and the auxiliary system, which generates subpressure in the left cylinder chamber. The measuring system allows measurement of the total force of connecting rod retraction. Since the measuring system was unable to deal with subpressures above $0.85 \%$, another system was designed and constructed to allow work with subpressures close to 'absolute' vacuum. This new system had pneumatic cylinders of larger capacity, allowing generation of vacuum in the initial volume of the measuring system. Main parts of this system are the two pneumatic cylinders (4) and (6), with pistons of $125 \mathrm{~mm}$ diameter, and piston stroke of $320 \mathrm{~mm}$, controlled by the accompanying control system. Connecting rods are linked by a stiff connection (5), so that the retraction of connecting rod (6) is caused by the extension of connecting rod (4), and vice versa. Pneumatic cylinder (4) is linked up with the compressor unit (1) providing the required pressure to the system, which can be monitored by a manometer (2). Valve (3) regulates the movement direction of the drive cylinder piston (4). When the connecting rod of the pneumatic cylinder (6) is in the position which enables minimal volume, measuring system is connected via hose, coupling and valve. Retraction of cylinder piston (4) is enabled by compressed air which is supplied behind the piston and into the cylinder (4). This enables piston (6) to be extended, which results in the generation of subpressure in the measuring system, once valves (7) and (8) are open. In order to attain as high subpressure level as possible, this procedure is repeated several times. To reduce the initial volume and attain sufficient subpressure, measuring system piston is brought into its starting position, which corresponds to the minimal air volume in the system at the front of the piston.

Once the measuring system is linked up to the computer (13), which allows storage of measured force data, control unit potentiometer is used to regulate the 
desired retraction speed of the connecting rod. In addition, by opening the compensation valve, it is possible to control the increase of system subpressure, i.e., increase of volume, due to piston retraction. Proper valve setting is necessary in order to provide constant subpressure level in the system, which can be monitored on a vacuum meter.
Stepper motor retracts the cylinder connecting rod, while the dynamometer performs acquisition of the actual force magnitude. The monitored force value data are stored in a data base through data acquisition system. This system allows subpressures to be attained which are very close to absolute vacuum.

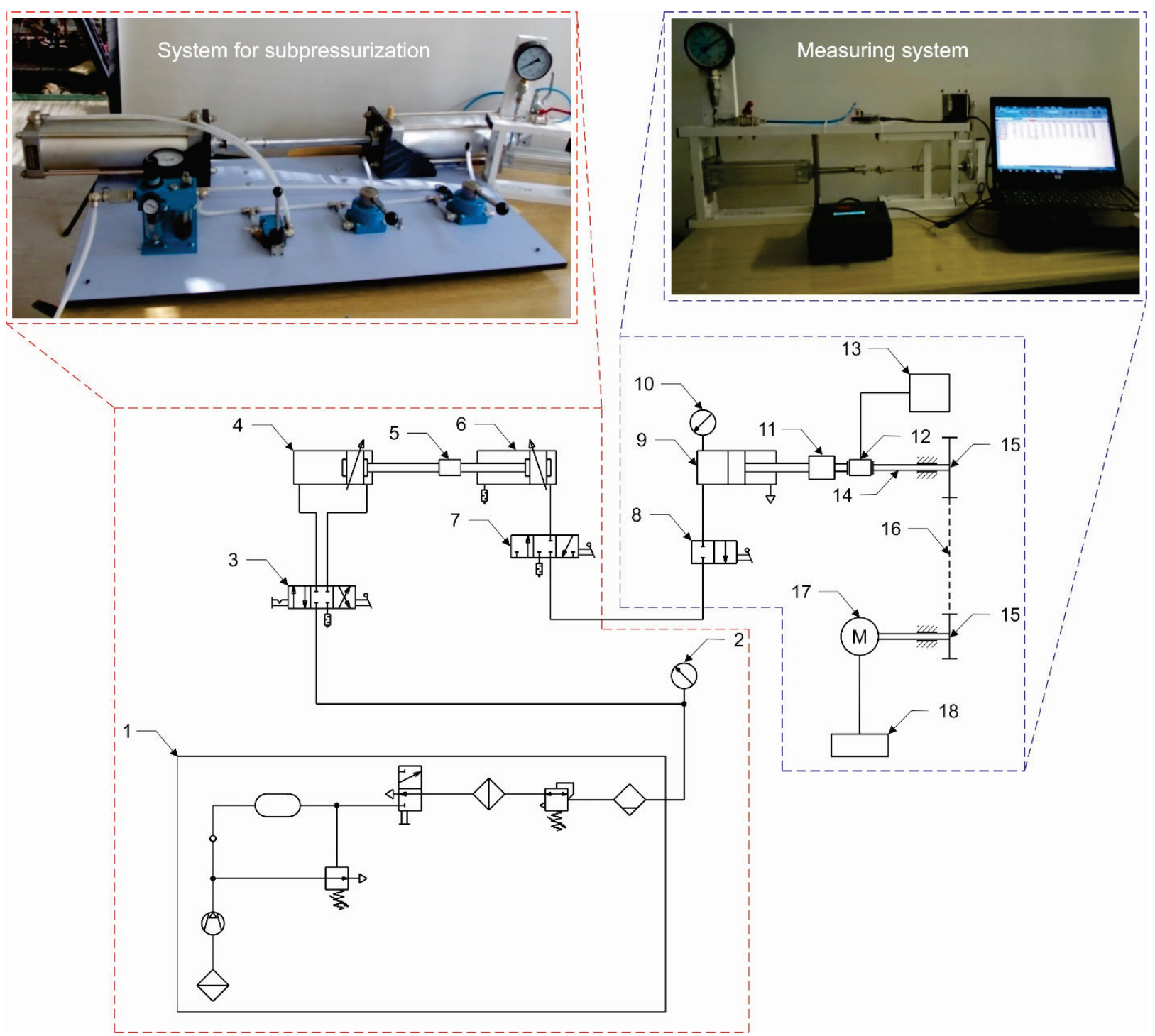

Figure 3 Schematic representation of the experimental system

\section{RESULTS}

Experimental investigations were conducted in order to determine relationship of the friction force between sealing rings and the pneumatic cylinder on the one side, and the cylinder subpressure level and piston retraction speed, on the other. All experiments were performed at room temperature, $23 \pm 0,5{ }^{\circ} \mathrm{C}$, in three repetitions.

The piston and connecting rod sealing rings were made of acrylonitrile butadiene rubber (NBR), with 70 Shore hardness. The dimensions of the piston and connecting rod were in compliance with the ASTM standard.

The plan of experiment demanded experiments to be performed from largest to lowest subpressure values.

Shown in table 1 are the mean total friction force values $\left(\bar{F}_{\mu}\right)$ obtained for 12 different connecting rod retraction speeds $(v)$, at 9 different subpressure levels.
The values of mean total friction force $\left(\bar{F}_{\mu}\right)$ correspond to the sums of mean value friction force components obtained for the friction between piston sealing ring and cylinder, and the mean value friction force between connecting rod and its sealing ring. In order to determine the influence of subpressure levels in cylinder, on the sliding friction force between the piston sealing ring and cylinder, it is necessary to subtract the friction force between connecting rod and sealing ring from the mean total friction force values $\bar{F}_{\mu}$.

Experimental determination of sliding friction force between connecting rod and sealing ring $\left(F_{\mu c}\right)$ was conducted with the almost identical measuring apparatus, the only difference being the piston which was removed from the connecting rod, so that the total friction force represented the friction between connecting rod and 
sealing ring $\left(F_{\mu c}\right)$. The results obtained show that the sliding friction force between connecting rod and sealing ring $\left(F_{\mu c}\right)$ is approximately constant, regardless of the retraction speed (Figure 4). Analysis of the graph in Figure 4 reveals that the influence of retraction speed on the sliding friction force between connecting rod and sealing ring $\left(F_{\mu c}\right)$ is insignificant, thus this mean value friction force can be considered constant and approximately equal to $0,1 \mathrm{daN}$.

Table 1 Mean values of the total friction force as the function of pressure difference and connecting rod retraction speed

\begin{tabular}{|c|c|c|c|c|c|c|c|c|c|c|c|c|}
\hline \multirow{3}{*}{$\Delta p /$ bar } & \multicolumn{12}{|c|}{$v / \mathrm{mm} / \mathrm{min}$} \\
\hline & 1,3 & 3,02 & 4,67 & 9,1 & 14,03 & 20,5 & 36 & 50,4 & 87,04 & 137,42 & 193,08 & 236 \\
\hline & \multicolumn{12}{|c|}{$\bar{F}_{\mu} / \mathrm{daN}$} \\
\hline 0,99 & 2,04 & 2,13 & 2,15 & 2,17 & 2,10 & 2,01 & 1,92 & 1,88 & 1,82 & 1,75 & 1,68 & 1,61 \\
\hline 0,9 & 1,91 & 1,92 & 2,04 & 2,07 & 2,02 & 1,95 & 1,85 & 1,80 & 1,74 & 1,67 & 1,61 & 1,53 \\
\hline 0,8 & 1,92 & 1,99 & 2,00 & 2,02 & 1,96 & 1,89 & 1,80 & 1,74 & 1,68 & 1,61 & 1,53 & 1,46 \\
\hline 0,7 & 1,90 & 1,94 & 1,92 & 1,94 & 1,91 & 1,83 & 1,74 & 1,70 & 1,65 & 1,57 & 1,51 & 1,44 \\
\hline 0,6 & 1,80 & 1,91 & 1,86 & 1,88 & 1,86 & 1,76 & 1,68 & 1,65 & 1,59 & 1,52 & 1,44 & 1,36 \\
\hline 0,5 & 1,80 & 1,85 & 1,86 & 1,87 & 1,84 & 1,70 & 1,60 & 1,54 & 1,48 & 1,39 & 1,32 & 1,28 \\
\hline 0,4 & 1,77 & 1,82 & 1,83 & 1,85 & 1,83 & 1,68 & 1,56 & 1,49 & 1,41 & 1,34 & 1,26 & 1,18 \\
\hline 0,3 & 1,75 & 1,76 & 1,83 & 1,84 & 1,78 & 1,66 & 1,51 & 1,43 & 1,32 & 1,20 & 1,11 & 1,03 \\
\hline 0,2 & 1,61 & 1,71 & 1,73 & 1,76 & 1,69 & 1,57 & 1,43 & 1,35 & 1,27 & 1,17 & 1,08 & 1,00 \\
\hline 0 & 1,47 & 1,56 & 1,58 & 1,61 & 1,55 & 1,47 & 1,33 & 1,26 & 1,17 & 1,06 & 0,96 & 0,86 \\
\hline
\end{tabular}

Table 2 Influence of pressure difference, and retraction speed of connecting rod on the mean value sliding friction force between piston sealing ring and cylinder

\begin{tabular}{|c|c|c|c|c|c|c|c|c|c|c|c|c|}
\hline \multirow{3}{*}{$\Delta p /$ bar } & \multicolumn{12}{|c|}{$v / \mathrm{mm} / \mathrm{min}$} \\
\hline & 1,3 & 3,02 & 4,67 & 9,1 & 14,03 & 20,5 & 36 & 50,4 & 87,04 & 137,42 & 193,08 & 236 \\
\hline & \multicolumn{12}{|c|}{$\bar{F}_{\mu k} / \mathrm{daN}$} \\
\hline 0,99 & 1,94 & 2,03 & 2,05 & 2,07 & 2,00 & 1,91 & 1,82 & 1,78 & 1,72 & 1,65 & 1,58 & 1,51 \\
\hline 0,9 & 1,81 & 1,82 & 1,94 & 1,97 & 1,92 & 1,85 & 1,75 & 1,70 & 1,64 & 1,57 & 1,51 & 1,43 \\
\hline 0,8 & 1,82 & 1,89 & 1,90 & 1,92 & 1,86 & 1,79 & 1,70 & 1,64 & 1,58 & 1,51 & 1,43 & 1,36 \\
\hline 0,7 & 1,80 & 1,84 & 1,82 & 1,84 & 1,81 & 1,73 & 1,64 & 1,60 & 1,55 & 1,47 & 1,41 & 1,34 \\
\hline 0,6 & 1,70 & 1,81 & 1,76 & 1,78 & 1,76 & 1,66 & 1,58 & 1,55 & 1,49 & 1,42 & 1,34 & 1,26 \\
\hline 0,5 & 1,70 & 1,75 & 1,76 & 1,77 & 1,74 & 1,60 & 1,50 & 1,44 & 1,38 & 1,29 & 1,22 & 1,18 \\
\hline 0,4 & 1,67 & 1,72 & 1,73 & 1,75 & 1,73 & 1,58 & 1,46 & 1,39 & 1,31 & 1,24 & 1,16 & 1,08 \\
\hline 0,3 & 1,65 & 1,66 & 1,73 & 1,74 & 1,68 & 1,56 & 1,41 & 1,33 & 1,22 & 1,10 & 1,01 & 0,93 \\
\hline 0,2 & 1,51 & 1,61 & 1,63 & 1,66 & 1,59 & 1,47 & 1,33 & 1,25 & 1,17 & 1,07 & 0,98 & 0,90 \\
\hline 0 & 1,37 & 1,46 & 1,48 & 1,51 & 1,45 & 1,37 & 1,23 & 1,16 & 1,07 & 0,96 & 0,86 & 0,76 \\
\hline
\end{tabular}

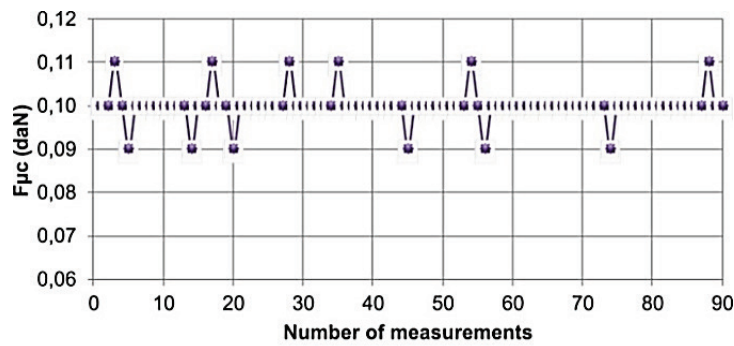

a)

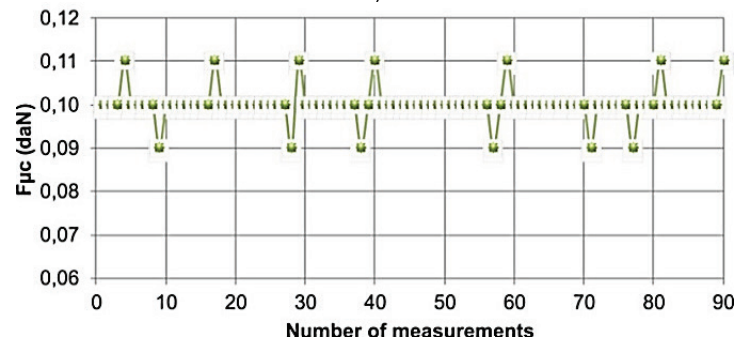

b)

Figure 4 Sliding friction force between connecting rod and sealing ring a) sliding speed $1,3 \mathrm{~mm} / \mathrm{min}$, b) sliding speed $236 \mathrm{~mm} / \mathrm{min}$

If the total registered mean value friction force, $\bar{F}_{\mu}$, is reduced by the mean value sliding friction force between connecting rod and sealing ring, $\bar{F}_{\mu c}$, the remaining component represents the mean value friction force between the piston sealing ring and inner cylinder wall, $\bar{F}_{\mu k}$ (Tab. 2).
The values in Tab. 2, are represented by the graph which shows the dependence of mean value sliding friction force between piston sealing ring and cylinder on the retraction speed of connecting rod, for various subpressure values (Fig. 5).

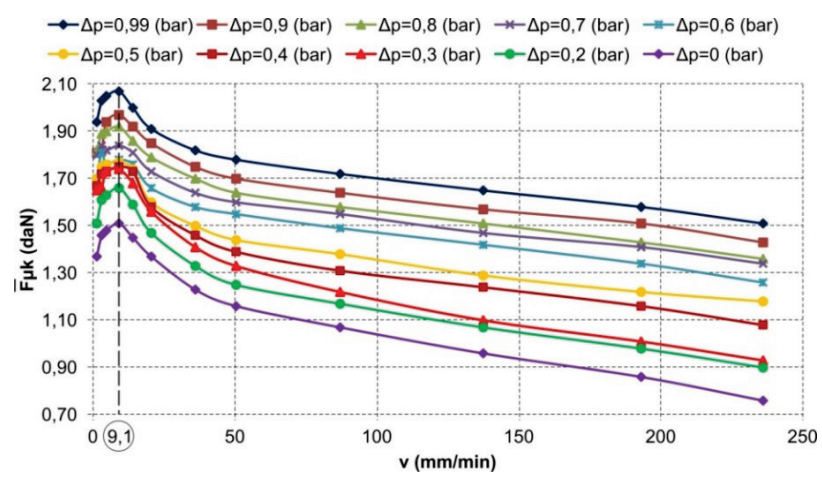

Figure 5 Mean value sliding friction force between piston sealing ring and cylinder on the retraction speed of connecting rod, for various subpressure values

\section{DISCUSSION}

The rising trend of friction force at piston speeds up to $9,1 \mathrm{~mm} / \mathrm{min}$ is present in all conducted experiments, for all subpressure values in cylinder. After the sudden increase of friction coefficient, there is also a sudden drop in the friction force, after which the friction force decreases in an approximately linear fashion with the increase of the piston sliding speed on the cylinder wall. 
Analysis of diagram in Fig. 5, yields conclusion that mean value friction force between sealing ring and cylinder wall drops with the increase of piston sliding speed. The initial increase of friction force at the very beginning of measurement can be attributed to adhesion of the sealing ring to cylinder walls. At the moment when the piston begins its movement, that force has a sudden drop, since the sealing ring slides over the roughness profile peaks, providing free passage to the air through profile valleys, from the high pressure- to low pressure zone. Due to increase of connection rod retraction speed, and owing to the stochastic nature of the roughness profile change, the air passes through the pressure gradient with increasing efficiency, creating an air film which reduces contact surface between sealing ring and cylinder wall, thus decreasing the resulting sliding friction force. In addition, the geometric form of the sealing ring provides good sealing of cylinders at higher pressures by distributing the load over the entire ring surface area, which, in turn, presses the ring against the cylinder walls. Due to pressure difference, in this experiment force vector has the opposite direction, thus allowing the ring to contract and form an air film between the sealing ring and cylinder wall. The influx of air into the subpressure zone increases with the piston retraction, i.e., the increase of cylinder volume in front of the piston.

From the diagram in Fig. 5, one can also see the drop in friction force due to subpressure drop in the cylinder, i.e., the difference between the atmospheric pressure and pressure inside the cylinder. This leads to conclusion that friction force increases with lower system pressures, which is also corroborated by the previously discussed literature sources.

The increase of friction force with the pressure drop in the system can be partly attributed to the inhibition of oxide layers on the contact surface interface, due to lower pressure. Besides, in such conditions sealing rings undergo additional compression, which, in turn, increases the friction force. Based on Tab. 2 it is obvious that the friction force increased by $41,6 \%$ when the sliding speed was $v=$ $1.3 \mathrm{~mm} / \mathrm{s}$, and pressure difference of $\Delta p=0,99$ bar. Also, that increase was $97,8 \%$ for the same pressure difference $(\Delta p=0,99)$, and $v=236 \mathrm{~mm} / \mathrm{min}$. This brings attention to the influence of piston sliding speed on the friction force, at higher pressured differences in cylinder.

Analysis of the equipment used in this experiment, leads to conclusion that measurement errors were minimized, due to flexible link between the connecting rod and dynamometer, which eliminated the prestressing of the measuring instrument. In this way, initial conditions were always the same and did not influence the results of measurements. Connecting rod retraction speed was constant, while the variations in pressure differences during the process of measurement, were monitored and did not significantly vary from the nominal values.

\section{CONCLUSION}

There are numerous technical systems which operate under high vacuum. It is therefore important to know tribological characteristics of component materials within tribo-mechanical systems which operate under conditions of high vacuum. That said, the results discussed in this study bring to light the phenomenon of higher friction forces present in the operation of pneumatic cylinders under high vacuum. It should be noted that, under high vacuum, friction forces significantly increase in the presence of higher sliding speeds.

Future investigations should be directed towards determination of friction force variations under high vacuum, at high sliding speeds of piston sealing ring over the cylinder walls. Due to dynamic effect of the friction force, future investigation shall be directed towards development of a mathematical friction model.

\section{REFERENCES}

[1] Cai, Z., Zhu, M., Zhen, J., Jin, X., \& Zhou Z. (2009). Torsional fretting behaviors of LZ50 steel in air and nitrogen. Tribology International, 42(11-12), 1676-1683. https://doi.org/10.1016/j.triboint.2009.04.031

[2] Singla, A. \& Chauhan, A. (2016). Evaluation of Oil Film Pressure and Temperature of an Elliptical Journal Bearing An Experimental Study. Tribology in Industry, 38(1), 74-82.

[3] Velkavrh,. I., Ausserer, F., Klien, S., Voyer, J., Ristow, A., Brenner, J., Foret, P., \& Diem, A. (2016). The influence of temperature on friction and wear of unlubricated steel/steel contacts in different gaseous atmospheres. Tribology International, 98, 155-171. https://doi.org/10.1016/j.triboint.2016.02.022

[4] Chaudhry, V. \& Kailas, S.V. (2013). Damage quantification under sliding and seizure condition using first-of-a-kind fretting machine. Wear, 305(1-2), 140-154. https://doi.org/10.1016/j.wear.2013.04.003

[5] Chen, R., Iwabuchi, A., \& Shimizu, T. (2001). Effects of ambient pressure on fretting friction and wear behavior between SUS 304 steels. Wear, 249(5-6), 379-388. https://doi.org/10.1016/s0043-1648(01)00547-6

[6] Chaudhry, V. \& Kailas, S.V. (2013). Fretting studies on selfmated stainless steel and chromium carbide coated surfaces under controlled environment conditions. Wear, 301(1-2), 524-539. https://doi.org/10.1016/j.wear.2013.01.084

[7] Hirsch, M. R. \& Neu, R. W. (2013). Influence of temperature on the fretting response between AISI 301 stainless steel and AISI 52100 steel. Tribology International, 68, 77-84. https://doi.org/10.1016/j.triboint.2012.11.004

[8] Pearson, S. R., Shipway, P. H., Abere, J. O., \& Hewitt, R. A. A. (2013). The effect of temperature on wear and friction of a high strength steel in fretting. Wear, 303(1-2), 622-631. https://doi.org/10.1016/j.wear.2013.03.048

[9] Mishina, H. (1992). Atmospheric characteristics in friction and wear of metals. Wear, 152(1), 99-110. https://doi.org/10.1016/0043-1648(92)90207-0

[10] Mishina, H. (1995). Chemisorption of diatomic gas molecules and atmospheric characteristics in adhesive wear and friction of metals. Wear, 180(1-2), 1-7. https://doi.org/10.1016/0043-1648(95)80003-4

[11] Bowden, F. \& Tabor, D. (2008). The friction and lubrication of solids. Oxford: Clarendon Press.

[12] Rigney, D.A., \& Hirth, J.P. (1979). Plastic deformation and sliding friction of metals. Wear, 53(2), 345-370. https://doi.org/10.1016/0043-1648(79)90087-5

[13] Iwabuchi, A., Kayaba, T., \& Kato, K. (1983). Effect of atmospheric pressure on friction and wear of $0.45 \% \mathrm{C}$ steel in fretting. Wear, 91(3), 289-305. https://doi.org/10.1016/0043-1648(83)90074-1

[14] Demizu, K., Wadabayashi, R., \& Ishigaki, H. (1990). Dry Friction of Oxide Ceramics against Metals: The Effect of Humidity. Tribology Transactions, 33(4), 505-510. https://doi.org/10.1080/10402009008981982 
[15] Lancaster, J. K. (1990). A review of the influence of environmental humidity and water on friction, lubrication and wear. Tribology International, 23(6), 371-389. https://doi.org/10.1016/0301-679x(90)90053-r

[16] Cai, Z., Zhu, M., Shen, H., Zhou, Z., \& Jin, X. (2009). Torsional fretting wear behaviour of 7075 aluminium alloy in various relative humidity environments. Wear, 267(1-4), 330-339. https://doi.org/10.1016/j.wear.2009.01.024

[17] Stifter, T., Marti, O., \& Bhushan, B. (2000). Theoretical investigation of the distance dependence of capillary and van der Waals forces in scanning force microscopy. Physical Review B, 62(20), 13667-13673. https://doi.org/10.1103/physrevb.62.13667

[18] Bistac, S., Schmitt, M., Ghorbal, A., Gnecco, E., \& Meyer, E. (2008). Nano-scale friction of polystyrene in air and in vacuum. Polymer, 49(17), 3780-3784. https://doi.org/10.1016/j.polymer.2008.06.032

[19] Tzeng, Y. (1993). Very low friction for diamond sliding on diamond in water. Applied Physics Letters, 63(26), 35863588. https://doi.org/10.1063/1.110762

[20] Zhao, Y., Yue, W., Lin, F., Wang, C., \& Wu, Z. (2015). Friction and wear behaviors of polycrystalline diamond under vacuum conditions. International Journal of Refractory Metals and Hard Materials, 50, 43-52. https://doi.org/10.1016/j.jirmhm.2014.11.008

[21] Miki, H., Yoshida, N., Bando, K., Takeno, T., Abe, T., \& Takagi, T. (2008). Atmosphere dependence of the frictional wearing properties of partly-polished polycrystalline diamonds. Diamond and Related Materials, 17(4-5), 868872. https://doi.org/10.1016/j.diamond.2007.08.033

[22] De Barros Bouchet, M. I., Zilibotti, G., Matta, C., Righi, M. C., Vandenbulcke, L., Vacher, B., \& Martin, J. M. (2012). Friction of Diamond in the Presence of Water Vapor and Hydrogen Gas. Coupling Gas-Phase Lubrication and FirstPrinciples Studies. Journal of Physical Chemistry $C$, 116(12), 6966-6972. https://doi.org/10.1021/jp211322s

[23] Miyoshi, K. (1999). Considerations in vacuum tribology (adhesion, friction, wear, and solid lubrication in vacuum). Tribology International, 32(11), 605-616. https://doi.org/10.1016/s0301-679x(99)00093-6

[24] Kucukomeroglu, T., Purcek, G., Saray, O., \& Kara, L. (2008). Investigation of friction and wear behaviours of CuSn10 alloy in vacuum. Journal of Achievements in Materials and Manufacturing Engineering, 30(2), 172-176.

[25] Kucukomeroglu, T. \& Kara, L. (2014). The friction and wear properties of $\mathrm{CuZn} 39 \mathrm{~Pb} 3$ alloys under atmospheric and vacuum conditions. Wear, 309(1-2), 21-28. https://doi.org/10.1016/j.wear.2013.10.003

[26] Persson, B. N. (2001). Theory of rubber friction and contact mechanics. Journal of Chemical Physics, 115(8), 3840 3861. https://doi.org/10.1063/1.1388626

[27] Arjmand, M. \& Shojaei, A. (2011). Tribological Characteristics of Rubber-Based Friction Materials. Tribology Letters, 41(2), 325-336. https://doi.org/10.1007/s11249-010-9715-0

[28] Anyszka, R., Bielinski, D. M., \& Strzelecki, D. (2015). Tribological Properties of Silicone Rubber-Based Ceramizable Composites Destined for Wire Covers. Part I. Studies of Block-On-Ring Friction Contact. Tribology in Industry, 37(2), 154-160.

[29] Anyszka, R., Bielinski, D. M., Imiela, M., Sicinski, M., Gozdek, T., \& Strzelecki, D. (2016). Tribological Properties of Silicone Rubber-Based Ceramizable Composites Destined for Wire Covers. Part II. Studies of Ball-on-Plate, Plate-on-Plate and Ring-on-Plate Friction Contact. Tribology in Industry, 38(3), 332-337.

[30] Deladi, E. L., de Rooij, M. B., \& Schipper, D. J. (2007). Modelling of static friction in rubber-metal contact. Tribology International, 40(4), 588-594. https://doi.org/10.1016/j.triboint.2005.11.007
[31] Bielsa, J. M., Canales, M., Martinez, F. J., \& Jimenez, M. A. (2010). Application of finite element simulations for data reduction of experimental friction tests on rubber-metal contacts. Tribology International, 43(4), 785-795 https://doi.org/10.1016/j.triboint.2009.11.005

[32] Ke, Y., Yao, X., Yang, H., Ma, Y., \& Liu, Y. (2017). The compression and friction of tubular rubber seal under the curved surface loading. Proceedings of the Institution of Mechanical Engineers. Part J: Journal of Engineering Tribology, 231(1), 14-22. https://doi.org/10.1177/1350650116645028

[33] Zhang, H. \& Zhang, J. (2016). Static and Dynamic Sealing Performance Analysis of Rubber D-Ring Based on FEM. Journal of Failure Analysis and Prevention, 16(1), 165-172. https://doi.org/10.1007/s11668-016-0066-5

[34] Belforte, G., Manuello Bertetto, A., \& Mazza, L. (2013). Test rig for friction force measurements in pneumatic components and seals, Proceedings of the Institution of Mechanical Engineers. Part J: Journal of Engineering Tribology, 227(1), 43-59. https://doi.org/10.1177/1350650112453522

[35] Mazza, L. \& Belforte, G. (2017). Analytical/Experimental Study of the Contribution of Individual Seals to Friction Force in Pneumatic Actuators. Journal of Tribology, 139(2), 022202. https://doi.org/10.1115/1.4033365

[36] Tran, X. B. \& Yanada, H. (2013). Dynamic Friction Behaviors of Pneumatic Cylinders, Intelligent Control and Automation, 4, 180-190. https://doi.org/10.4236/ica.2013.42022

[37] Tran, X. B., Dao, H. T., \& Tran, K. D. (2016). A new mathematical model of friction for pneumatic cylinders, Proceedings of the Institution of Mechanical Engineers. Part C: Journal of Mechanical Engineering Science, 230(14), 2399-2412. https://doi.org/10.1177/0954406215594828

[37] Belforte, G., Mattiazzo, G., Mauro, S., \& Tokashiki, L.R. (2006). Measurement of friction force in pneumatic cylinders, Lubrication Science, 10(1), 33-48. https://doi.org/10.1002/tt.3020100104

Contact information:

Branko TADIC, Dr. Sc.

University of Kragujevac, Faculty of Engineering

Sestre Janjic 6, Kragujevac, Serbia

Milutin ZIVKOVIC, Dr. Sc

Higher Technical School of Mechanical Engineering,

Radoja Krstica 19, Trstenik, Serbia

Goran SIMUNOVIC, Dr. Sc.

Josip Juraj Strossmayer University of Osijek, Mechanical Engineering Faculty in Slavonski Brod

Trg Ivane Brlic Mazuranic 2, 35000 Slavonski Brod, Croatia

Vladimir KOCOVIC, MSc

University of Kragujevac, Faculty of Engineering

Sestre Janjic 6, Kragujevac, Serbia

Tomislav SARIC, Dr. Sc.

Josip Juraj Strossmayer University of Osijek, Mechanical Engineering Faculty in Slavonski Brod

Trg Ivane Brlic Mazuranic 2, 35000 Slavonski Brod, Croatia

Djordje VUKELIC, Dr. Sc.

(Corresponding author)

University of Novi Sad, Faculty of Technical Sciences

Trg Dositeja Obradovica 6, Novi Sad, Serbia

vukelic@uns.ac.rs 